\title{
28 Research Square \\ Readiness to Implement Symptom Management Care Pathways in Pediatric Cancer
}

\section{Lee Dupuis}

The Hospital for Sick Children

\section{Allison Grimes}

UT Health San Antonio: The University of Texas Health Science Center at San Antonio

\section{Emily Vettese}

The Hospital for Sick Children

\section{Lisa M. Klesges}

Washington University School of Medicine in Saint Louis: Washington University in St Louis School of

Medicine

Lillian Sung ( $\square$ lillian.sung@sickkids.ca )

Hospital for Sick Children https://orcid.org/0000-0003-0951-3091

\section{Research}

Keywords: pediatric oncology, symptom management, care pathway implementation, COVID-19 pandemic

Posted Date: December 30th, 2020

DOl: https://doi.org/10.21203/rs.3.rs-136225/v1

License: (c) (1) This work is licensed under a Creative Commons Attribution 4.0 International License.

Read Full License 


\section{Abstract}

Background: To describe barriers to pediatric cancer symptom management care pathway implementation and the impact of the COVID-19 pandemic on clinical research evaluating their implementation.

Methods: We included 25 pediatric oncology hospitals in the United States that supported a grant submission to perform a cluster randomized trial in which the intervention encompassed care pathways for symptom management. A survey was distributed to site principal investigators to measure contextual elements related to care pathway implementation. Questions included the inner setting measures of the Consolidated Framework for Implementation Research (CFIR), study-specific potential barriers and the impact of the COVID-19 pandemic on clinical research. The Wilcoxon rank sum test was used to compare characteristics of institutions that agreed that their department supported the implementation of symptom management care pathways vs. institutions that did not agree.

Results: Of the 25 sites, one withdrew because of resource constraints and one did not respond, leaving 23 institutions. Among the seven CFIR constructs, the least supported was implementation climate; $57 \%$ agreed there was support, $39 \%$ agreed there was recognition and $39 \%$ agreed there was prioritization for symptom management care pathway implementation at their institution. Most common barriers were lack of person-time to create care pathways and champion their use (35\%), lack of interest from physicians (30\%) and lack of information technology resources (26\%). Most sites reported no negative impact of the COVID-19 pandemic across research activities. Sites with fewer pediatric cancer patients were more likely to agree that staff are supported to implement symptom management care pathways $(P=0.003)$.

Conclusions: The most commonly reported barriers to implementation were lack of support, recognition and prioritization. The COVID-19 pandemic was not a major barrier to clinical research activities in pediatric oncology.

Clinical Trial Registration: NCT04614662

\section{Contributions To The Literature}

- Among the seven Consolidated Framework for Implementation Research constructs, the least supported was implementation climate with poor, recognition of prioritization for symptom management care pathway implementation

- Most common barriers to care pathway implementation were lack of person-time to create care pathways and champion their use (35\%), lack of interest from physicians $(30 \%)$ and lack of information technology resources $(26 \%)$

- The COVID-19 pandemic was not a major barrier to clinical research activities in pediatric oncology 


\section{Background}

Most pediatric patients receiving cancer treatments experience bothersome symptoms that are poorly documented and often not treated.[1, 2] Symptom control is important as there is a strong correlation between increasing symptom burden and inferior quality of life.[1] Improving symptom control is likely to require multiple approaches including systematic symptom screening, symptom feedback to healthcare professionals and adherence to symptom management clinical practice guidelines (CPGs).[3, 4] To address symptom screening, we developed the Symptom Screening in Pediatrics Tool (SSPedi), which measures the degree of bother for 15 symptoms considered most important by patients. [5-7] We then developed Supportive care Prioritization, Assessment and Recommendations for Kids (SPARK), which is a web-based application that consists of a symptom screening component centered on SSPedi and a supportive care CPG component.[8-10]

To test whether SPARK can improve symptom control and quality of life for pediatric patients with cancer, we were awarded operating grants from the National Institutes of Health (1R01CA251112) and the Canadian Institutes of Health Research (PJT 169165) to perform a cluster randomized trial of 20 institutions in the United States. This trial will randomize 10 sites to intervention and 10 sites to control (usual care) groups. The intervention will include prompts to complete symptom screening three times weekly for newly diagnosed pediatric patients with cancer, symptom feedback to the primary healthcare team and adaptation of care pathways for symptom management based upon CPGs. Thus, intervention sites will need to adapt and implement evidenced-based care pathways. Planning of the trial started concurrently with the coronavirus disease pandemic (COVID-19)[11, 12] thus adding potential barriers.

To begin to understand potential barriers relevant to the planned trial including care pathway implementation, we circulated a survey to sites that had committed to the trial at the grant submission stage from which the 20 participating sites would be chosen. Objectives were to describe barriers to pediatric cancer symptom management care pathway implementation and the impact of the COVID-19 pandemic on clinical research evaluating their implementation.

\section{Methods}

The study was approved by the Research Ethics Board of The Hospital for Sick Children. The sites were 25 pediatric oncology hospitals in the United States supporting a grant submission to conduct a cluster randomized trial focused on improving symptom control in pediatric cancer patients. The institutions were chosen to reflect variation in pediatric vs. mixed adult and pediatric sites and based upon previous research collaborations. One component of the intervention is the institution-specific adaptation of symptom management care pathways that are based upon CPGs. The purposes of the baseline survey were to facilitate site selection ( 20 of the 25 potential sites would be chosen), to measure baseline characteristics of participating sites and to anticipate barriers and facilitators to trial conduct and care pathway implementation that could influence implementation processes. 
CPGs are statements developed to facilitate healthcare-related decisions; they are the foundations for translating evidence to clinical practice.[13] The components underpinning CPG development include a systematic review of the literature and a panel that weighs the benefits and harms of different treatment options to arrive at recommendations.[13-15] Care pathways are tools that can improve CPG implementation. They can be defined as "structured multidisciplinary care plans which detail essential steps in the care of patients with a specific clinical problem."[16]

The survey measured baseline characteristics including institution, patient and healthcare professional characteristics. In order to understand potential barriers to symptom management care pathway implementation, we used three approaches. First, we used the Consolidated Framework for Implementation Research (CFIR).[17, 18] The CFIR is a conceptual framework that includes factors that may influence intervention implementation. We focused on the inner setting measures that include the following constructs: culture, culture stress, culture effort, implementation climate, learning climate, leadership engagement and available resources. Of these constructs, implementation climate was thought to be potentially particularly important to successful implementation given its specificity to the task. Each of the questions was rated on a 5 -point Likert scale consisting of $1=$ "strongly disagree"; $2=$ "disagree"; $3="$ neutral"; $4=$ "agree"; and $5=$ "strongly agree". We dichotomized those who agreed (score of 4 or 5) vs. those who were neutral or disagreed (score of 1,2 or 3). We also used a second set of questions that were specific to the proposed study and asked if the lack of the following were potential barriers to symptom management care pathway adaptation and implementation: person-time to create care pathways and champion their use; education and mentorship around care pathway use; hospital leadership support; interest from physicians; interest from allied health; information technology resources; and collaboration between different disciplines. These were rated on a 5-point Likert scale representing the degree to which they were a barrier: $1=$ "not at all"; $2=$ "a little"; $3=$ "somewhat"; $4=$ "a lot"; and $5=$ "extreme". Third, given the timing of the COVID-19 pandemic related to full grant funding (R01 notice of award July 2020), we also asked about the impact of the pandemic across the spectrum of clinical research activities.

The primary outcomes were related to support, recognition and prioritization of symptom management care pathway implementation from the CFIR implementation climate construct. The survey was disseminated to the participating sites by email and completed in REDCap. The respondents were the site principal investigators; they could consult with other institutional personnel to facilitate survey completion.

\section{Statistics}

Descriptive statistics were used to summarize baseline characteristics and potential barriers to symptom management care pathway implementation. We compared institutional characteristics of those that agreed that their department supports, recognizes and prioritizes the implementation of symptom 
management care pathways vs. those that did not agree using the Wilcoxon rank sum test. Analyses were performed using R studio version 3.6.1, The R Foundation for Statistical Computing.

\section{Results}

Of the 25 sites who supported grant submission, one withdrew because of institutional resource constraints and one did not complete the survey, leaving 23 institutions included in the analysis. The survey was completed between August 5, 2020 and September 9, 2020. Table 1 describes institutional, patient and healthcare professional characteristics. Within all institutions, health care professionals create orders in the electronic health record for symptom prevention and management. The median number of new pediatric cancer patients diagnosed annually was 90 (interquartile range (IQR) 63 to 200). All institutions were described as not-for-profit. The median number of physician full time equivalents was 9 (IQR 5 to 13). 
Table 1

Demographic Characteristics of Institutions ( $N=23)$

\begin{tabular}{|c|c|}
\hline & Value \\
\hline \multicolumn{2}{|l|}{ Institution Characteristics } \\
\hline Pediatric vs. Mixed Adult and Pediatric (\%) & 16 (70\%) \\
\hline Not-for-Profit vs. For-Profit (\%) & $23(100 \%)$ \\
\hline \multicolumn{2}{|l|}{ Patient Characteristics } \\
\hline Median Number Pediatric Cancer Patients Diagnosed Annually (IQR) & 90 (63 to 200$)$ \\
\hline \multicolumn{2}{|l|}{ Median Insurance Type Percentage (IQR) } \\
\hline Private & 48 (33 to 55$)$ \\
\hline Public & 50 (44 to 65$)$ \\
\hline No insurance & $1(0$ to 5$)$ \\
\hline Median Male Percentage (IQR) & $53(50$ to 56$)$ \\
\hline \multicolumn{2}{|l|}{ Median Race Percentage (IQR) } \\
\hline American Indian or Alaskan native & $0(0$ to 1$)$ \\
\hline Asian & 5 (3 to 10$)$ \\
\hline Black or African American & 10 (5 to 21$)$ \\
\hline Native Hawaiian or other pacific islander & $0(0$ to 1$)$ \\
\hline White & 70 (64 to 87$)$ \\
\hline Median Hispanic or Latino Ethnicity (IQR) & $26(11$ to 40$)$ \\
\hline \multicolumn{2}{|l|}{ Median Language Spoken Percentage (IQR) } \\
\hline English & 80 (71 to 90$)$ \\
\hline Spanish & 12 (7 to 20$)$ \\
\hline Other & $2(1$ to 5$)$ \\
\hline \multicolumn{2}{|l|}{ Healthcare Professional Characteristics } \\
\hline Median MD or DO Full Time Equivalents (IQR) & $9(5$ to 13$)$ \\
\hline Median Nurse Practitioner Full Time Equivalents (IQR) & 5 (2 to 10$)$ \\
\hline Median Physician Assistant Full Time Equivalents (IQR) & $1(0$ to 1$)$ \\
\hline
\end{tabular}

Abbreviations: MD, medical doctor; DO, doctor of osteopathy; IQR, interquartile range 


\begin{tabular}{|lc|}
\hline & Value \\
\hline Median MD or DO Years in Practice (IQR) & 11 (10 to 15) \\
\hline Median Nurse Practitioner Years in Practice (IQR) & 8 (4 to 10) \\
\hline Median Physician Assistant Years in Practice (IQR) & 3 (0 to 10) \\
\hline Abbreviations: MD, medical doctor; DO, doctor of osteopathy; IQR, interquartile range \\
\hline
\end{tabular}

Table 2 shows the results of the inner setting measures from the CFIR. Across most constructs, at least $70 \%$ of institutions agreed that the culture, climate, leadership and resources facilitated symptom management care pathway implementation. With respect to the implementation climate construct, less than $70 \%$ of respondents agreed or strongly agreed with the following positively framed statements: "department staff gets the support they need to implement care pathways for symptom management" (57\%), "department staff gets recognition for implementing care pathways for symptom management" $(39 \%)$ and "implementing care pathways for symptom management is a top priority of the department" (61\%). Respondents from $35 \%$ of institutions indicated that "staff members often showed signs of stress and strain". 
Table 2

Inner Setting Measures from the Consolidated Framework for Implementation Related to Symptom Management Care Pathways $(\mathrm{N}=23)$

n $\%$

\section{Culture}

People at all levels openly talk about what is and isn't working $20 \quad 87 \%$

Most people in this department are willing to change how they do things in response to $\quad 16 \quad 70 \%$ feedback from others

It is hard to get things to change in our department

$4 \quad 17 \%$

I can rely on the other people in this department to do their jobs well

$2191 \%$

Most of the people who work in our department seem to enjoy their work $20 \quad 87 \%$

Difficult problems are solved through face-to-face discussions $1983 \%$

We regularly take time to reflect on how we do things $1670 \%$

After trying something new, we take time to think about how it worked $17 \quad 74 \%$

People in this department operate as a real team

$20 \quad 87 \%$

\section{Culture Stress}

I am under too many pressures to do my job effectively

$14 \%$

Staff members often show signs of stress and strain

$835 \%$

The heavy workload here reduces program effectiveness

$5 \quad 22 \%$

Staff frustration is common here

$5 \quad 22 \%$

\section{Culture Effort}

People in this department always want to perform to the best of their abilities

People are enthusiastic about their work

People in our department get by with doing as little as possible

$0 \quad 0 \%$

People are prepared to make a special effort to do a good job

$2087 \%$

People in this department do not put more effort into their work than they have to

$0 \quad 0 \%$

\section{Implementation Climate}

Department staff are expected to help the institution meet its goal

Department staff gets the support they need to implement care pathways for symptom management

* $\mathrm{n}$ - number of respondents who agreed or strongly agreed 


\begin{tabular}{|c|c|c|}
\hline & $\mathrm{n}$ & $\%$ \\
\hline $\begin{array}{l}\text { Department staff gets recognition for implementing care pathways for symptom } \\
\text { management }\end{array}$ & 9 & $39 \%$ \\
\hline $\begin{array}{l}\text { Implementing care pathways for symptom management is a top priority of the } \\
\text { department }\end{array}$ & 14 & $61 \%$ \\
\hline
\end{tabular}

\section{Learning Climate}

We regularly take time to consider ways to improve how we do things

$20 \quad 87 \%$

People in our department actively seek new ways to improve how we do things

$2296 \%$

This department encourages everyone to share ideas

$2296 \%$

This department learns from its mistakes

$20 \quad 87 \%$

When we experience a problem in the department, we make a serious effort to figure

$2296 \%$ out what's really going on

\section{Leadership Engagement}

The department leadership makes sure that we have the time and space necessary to $\quad 19 \quad 83 \%$ discuss changes to improve care

Leadership in this department creates an environment where things can be accomplished

$1983 \%$

Department leadership promotes an environment that is an enjoyable place to work

$18 \quad 78 \%$

Leadership strongly supports department change efforts

$2191 \%$

\section{Available Resources}

In general, when there is agreement that change needs to happen in the department we have the necessary support in terms of: budget or financial resources

$17 \quad 74 \%$

In general, when there is agreement that change needs to happen in the department we 20 $87 \%$ have the necessary support in terms of: training

In general, when there is agreement that change needs to happen in the department we $\quad 16 \quad 70 \%$ have the necessary support in terms of: staffing

The following are available to make implementing care pathways for symptom management work in our department: patient awareness/need

The following are available to make implementing care pathways for symptom management work in our department: provider buy-in

The following are available to make implementing care pathways for symptom management work in our department: intervention team

* $\mathrm{n}$ - number of respondents who agreed or strongly agreed 
Table 3 shows additional barriers to implementing symptom management care pathways among respondents. The most common barriers (somewhat, a lot or extreme barrier) were as follows: lack of person-time to create care pathways and champion their use (35\%), lack of interest from physicians $(30 \%)$ and lack of information technology resources $(26 \%)$. Severe barriers (a lot or extreme barrier) were rare and the most common was the lack of person-time to create care pathways and champion their use (9\%). 
Table 3

Barriers to Developing and Implementing Care Pathways ( $N=23)$

\begin{tabular}{|c|c|c|}
\hline & $\mathrm{n}$ & $\%$ \\
\hline \multicolumn{3}{|c|}{ Lack of person-time to create care pathways and champion their use } \\
\hline Not at all or a little barrier & 15 & $65 \%$ \\
\hline Somewhat & 6 & $26 \%$ \\
\hline A lot or extreme barrier & 2 & $9 \%$ \\
\hline \multicolumn{3}{|c|}{ Lack of education and mentorship around care pathway use } \\
\hline Not at all or a little barrier & 18 & $78 \%$ \\
\hline Somewhat & 4 & $17 \%$ \\
\hline A lot or extreme barrier & 1 & $4 \%$ \\
\hline \multicolumn{3}{|c|}{ Lack of hospital leadership support } \\
\hline Not at all or a little barrier & 18 & $78 \%$ \\
\hline Somewhat & 5 & $22 \%$ \\
\hline A lot or extreme barrier & 0 & $0 \%$ \\
\hline \multicolumn{3}{|c|}{ Lack of interest from physicians } \\
\hline Not at all or a little barrier & 16 & $70 \%$ \\
\hline Somewhat & 7 & $30 \%$ \\
\hline A lot or extreme barrier & 0 & $0 \%$ \\
\hline \multicolumn{3}{|c|}{ Lack of interest from allied health } \\
\hline Not at all or a little barrier & 21 & $91 \%$ \\
\hline Somewhat & 2 & $9 \%$ \\
\hline A lot or extreme barrier & 0 & $0 \%$ \\
\hline \multicolumn{3}{|c|}{ Lack of information technology resources } \\
\hline Not at all or a little barrier & 17 & $74 \%$ \\
\hline Somewhat & 5 & $22 \%$ \\
\hline A lot or extreme barrier & 1 & $4 \%$ \\
\hline \multicolumn{3}{|c|}{ Lack of collaboration between different disciplines } \\
\hline Not at all or a little barrier & 18 & $78 \%$ \\
\hline
\end{tabular}




\begin{tabular}{|lcc|}
\hline & $\mathbf{n}$ & $\%$ \\
\hline Somewhat & 4 & $17 \%$ \\
\hline A lot or extreme barrier & 1 & $4 \%$ \\
\hline
\end{tabular}

Table 4 illustrates the impact of the COVID-19 pandemic on research activities at the institutions. Most sites reported no negative impact of the pandemic across research activities. The most common activities that were a lot more difficult or almost impossible were executing contracts (9\%), study activation (9\%) and accessing patients in person (9\%). 
Table 4

Impact of COVID-19 Pandemic on Clinical Research $(\mathrm{N}=23)$

\begin{tabular}{|c|c|c|}
\hline & $\mathbf{n}$ & $\%$ \\
\hline \multicolumn{3}{|l|}{ Obtaining institutional review board approval } \\
\hline Better than usual or no impact & 18 & $78 \%$ \\
\hline A little more difficult & 5 & $22 \%$ \\
\hline A lot more difficult or almost impossible & 0 & $0 \%$ \\
\hline \multicolumn{3}{|l|}{ Executing contracts } \\
\hline Better than usual or no impact & 17 & $74 \%$ \\
\hline A little more difficult & 4 & $17 \%$ \\
\hline A lot more difficult or almost impossible & 2 & $9 \%$ \\
\hline \multicolumn{3}{|l|}{ Study activation } \\
\hline Better than usual or no impact & 14 & $61 \%$ \\
\hline A little more difficult & 7 & $30 \%$ \\
\hline A lot more difficult or almost impossible & 2 & $9 \%$ \\
\hline \multicolumn{3}{|l|}{ Accessing patients in person } \\
\hline Better than usual or no impact & 13 & $57 \%$ \\
\hline A little more difficult & 8 & $35 \%$ \\
\hline A lot more difficult or almost impossible & 2 & $9 \%$ \\
\hline \multicolumn{3}{|l|}{ Accessing patients remotely in hospital } \\
\hline Better than usual or no impact & 21 & $91 \%$ \\
\hline A little more difficult & 2 & $9 \%$ \\
\hline A lot more difficult or almost impossible & 0 & $0 \%$ \\
\hline \multicolumn{3}{|l|}{ Accessing patients remotely at home } \\
\hline Better than usual or no impact & 19 & $83 \%$ \\
\hline A little more difficult & 4 & $17 \%$ \\
\hline A lot more difficult or almost impossible & 0 & $0 \%$ \\
\hline \multicolumn{3}{|l|}{ Accessing hospital systems } \\
\hline Better than usual or no impact & 19 & $83 \%$ \\
\hline
\end{tabular}




\begin{tabular}{|lll|}
\hline & $\mathbf{n}$ & $\%$ \\
\hline A little more difficult & 4 & $17 \%$ \\
\hline A lot more difficult or almost impossible & 0 & $0 \%$ \\
\hline Clinical research associate availability & & \\
\hline Better than usual or no impact & 14 & $61 \%$ \\
\hline A little more difficult & 9 & $39 \%$ \\
\hline A lot more difficult or almost impossible & 0 & $0 \%$ \\
\hline
\end{tabular}

Table 5 compares the attributes of sites that agreed that symptom management care pathway implementation was supported, recognized and prioritized vs. those that did not agree with these statements. Sites with fewer newly diagnosed cancer patients and those with fewer physician, nurse practitioner and physician assistant full time equivalents were significantly more likely to agree that their staff are supported. Sites with a larger percentage of black patients were significantly more likely to agree that their staff receives recognition for implementing symptom management care pathways and that implementation was a priority. 
Table 5

Support, Recognition and Priority of Care Pathway Implementation by Patient and Healthcare Professional Characteristics

\begin{tabular}{|c|c|c|c|}
\hline & Agree* & $\begin{array}{l}\text { Neutral or } \\
\text { Disagree }\end{array}$ & $\begin{array}{l}\mathrm{P} \\
\text { Value }\end{array}$ \\
\hline $\begin{array}{l}\text { Department staff gets the support they need to implement care } \\
\text { pathways for symptom management }\end{array}$ & $N=13$ & $N=10$ & \\
\hline Pediatric vs. Mixed Adult and Pediatric (\%) & $9(69 \%)$ & $7(70 \%)$ & 1.000 \\
\hline $\begin{array}{l}\text { Median Number Pediatric Cancer Patients Diagnosed Annually } \\
\text { (IQR) }\end{array}$ & $\begin{array}{l}66(50 \\
\text { to } 90)\end{array}$ & $\begin{array}{l}200(105 \text { to } \\
302)\end{array}$ & 0.003 \\
\hline \multicolumn{4}{|l|}{ Median Insurance Type Percentage (IQR) } \\
\hline Private & $\begin{array}{l}38(30 \\
\text { to } 50)\end{array}$ & $\begin{array}{l}51(43 \text { to } \\
57)\end{array}$ & 0.202 \\
\hline Public & $\begin{array}{l}59(50 \\
\text { to } 65)\end{array}$ & $\begin{array}{l}46(42 \text { to } \\
53)\end{array}$ & 0.225 \\
\hline No insurance & $\begin{array}{l}0(0 \text { to } \\
5)\end{array}$ & $2(1$ to 5$)$ & 0.276 \\
\hline Median Male Percentage (IQR) & $\begin{array}{l}55(50 \\
\text { to } 60)\end{array}$ & $\begin{array}{l}52(50 \text { to } \\
54)\end{array}$ & 0.281 \\
\hline \multicolumn{4}{|l|}{ Median Race Percentage (IQR) } \\
\hline American Indian or Alaskan native & $\begin{array}{l}0(0 \text { to } \\
2)\end{array}$ & $1(0$ to 1$)$ & 0.921 \\
\hline Asian & $\begin{array}{l}5(1 \text { to } \\
10)\end{array}$ & 5 (3 to 9$)$ & 0.573 \\
\hline Black or African American & $\begin{array}{l}20(8 \text { to } \\
23)\end{array}$ & 9 (5 to 17$)$ & 0.351 \\
\hline Native Hawaiian or other pacific islander & $\begin{array}{l}0(0 \text { to } \\
1)\end{array}$ & $1(0$ to 1$)$ & 0.297 \\
\hline White & $\begin{array}{l}70(55 \\
\text { to } 89)\end{array}$ & $\begin{array}{l}72(70 \text { to } \\
80)\end{array}$ & 1.000 \\
\hline Median Hispanic or Latino Ethnicity (IQR) & $\begin{array}{l}20(8 \text { to } \\
34)\end{array}$ & $\begin{array}{l}32(25 \text { to } \\
42)\end{array}$ & 0.291 \\
\hline \multicolumn{4}{|l|}{ Median Language Spoken Percentage (IQR) } \\
\hline English & $\begin{array}{l}80(72 \\
\text { to } 91)\end{array}$ & $\begin{array}{l}80(71 \text { to } \\
88)\end{array}$ & 0.852 \\
\hline
\end{tabular}

Abbreviations: IQR - interquartile range; MD - medical doctor; DO - doctor of osteopathy

* Rated on a 5-point Likert scale ranging from strongly disagree to strongly agree. Those who stated they agreed or strongly agreed were categorized as "agree" 


\begin{tabular}{|c|c|c|c|}
\hline & Agree* & $\begin{array}{l}\text { Neutral or } \\
\text { Disagree }\end{array}$ & $\begin{array}{l}P \\
\text { Value }\end{array}$ \\
\hline Spanish & $\begin{array}{l}12(3 \text { to } \\
20)\end{array}$ & $\begin{array}{l}14(10 \text { to } \\
22)\end{array}$ & 0.534 \\
\hline Median MD or DO Full Time Equivalents (IQR) & $\begin{array}{l}7(5 \text { to } \\
10)\end{array}$ & $13(9$ to 21$)$ & 0.014 \\
\hline Median Nurse Practitioner Full Time Equivalents (IQR) & $\begin{array}{l}2(1 \text { to } \\
5)\end{array}$ & $10(7$ to 11$)$ & 0.009 \\
\hline Median Physician Assistant Full Time Equivalents (IQR) & $\begin{array}{l}0(0 \text { to } \\
1)\end{array}$ & $1(0$ to 2$)$ & 0.033 \\
\hline Median MD or DO Years in Practice (IQR) & $\begin{array}{l}11(10 \\
\text { to } 15)\end{array}$ & $\begin{array}{l}11(10 \text { to } \\
15)\end{array}$ & 0.569 \\
\hline Median Nurse Practitioner Years in Practice (IQR) & $\begin{array}{l}5(2 \text { to } \\
8)\end{array}$ & 10 (7 to 12$)$ & 0.053 \\
\hline Median Physician Assistant Years in Practice (IQR) & $\begin{array}{l}0 \text { (0 to } \\
10)\end{array}$ & 5 (1 to 9$)$ & 0.448 \\
\hline $\begin{array}{l}\text { Department staff gets recognition for implementing care } \\
\text { pathways for symptom management }\end{array}$ & $N=9$ & $N=14$ & \\
\hline Pediatric vs. Mixed Adult and Pediatric (\%) & $7(78 \%)$ & $9(64 \%)$ & 0.824 \\
\hline $\begin{array}{l}\text { Median Number Pediatric Cancer Patients Diagnosed Annually } \\
\text { (IQR) }\end{array}$ & $\begin{array}{l}85(60 \\
\text { to } 110)\end{array}$ & $\begin{array}{l}105(67 \text { to } \\
200)\end{array}$ & 0.636 \\
\hline \multicolumn{4}{|l|}{ Median Insurance Type Percentage (IQR) } \\
\hline Private & $\begin{array}{l}41(30 \\
\text { to } 60)\end{array}$ & $\begin{array}{l}50(36 \text { to } \\
52)\end{array}$ & 0.850 \\
\hline Public & $\begin{array}{l}59(40 \\
\text { to } 65)\end{array}$ & $\begin{array}{l}48(45 \text { to } \\
60)\end{array}$ & 0.752 \\
\hline No insurance & $\begin{array}{l}0 \text { (0 to } \\
2)\end{array}$ & $2(0$ to 5$)$ & 0.204 \\
\hline Median Male Percentage (IQR) & $\begin{array}{l}55(50 \\
\text { to } 57)\end{array}$ & $\begin{array}{l}52(50 \text { to } \\
55)\end{array}$ & 0.723 \\
\hline \multicolumn{4}{|l|}{ Median Race Percentage (IQR) } \\
\hline American Indian or Alaskan native & $\begin{array}{l}0(0 \text { to } \\
2)\end{array}$ & $1(0$ to 1$)$ & 0.840 \\
\hline Asian & $\begin{array}{l}5(5 \text { to } \\
10)\end{array}$ & $4(1$ to 7$)$ & 0.098 \\
\hline \multicolumn{4}{|c|}{ Abbreviations: IQR - interquartile range; MD - medical doctor; DO - doctor of osteopathy } \\
\hline $\begin{array}{l}\text { * Rated on a 5-point Likert scale ranging from strongly disagre } \\
\text { they agreed or strongly agreed were categorized as "agree" }\end{array}$ & ongly a & e. Those wl & \\
\hline
\end{tabular}




\begin{tabular}{|c|c|c|c|}
\hline & Agree* & $\begin{array}{l}\text { Neutral or } \\
\text { Disagree }\end{array}$ & $\begin{array}{l}P \\
\text { Value }\end{array}$ \\
\hline Black or African American & $\begin{array}{l}20(10 \\
\text { to } 29)\end{array}$ & 8 (5 to 17$)$ & 0.037 \\
\hline Native Hawaiian or other pacific islander & $\begin{array}{l}1(0 \text { to } \\
2)\end{array}$ & $0(0$ to 1$)$ & 0.245 \\
\hline White & $\begin{array}{l}68(54 \\
\text { to } 70)\end{array}$ & $\begin{array}{l}75(70 \text { to } \\
90)\end{array}$ & 0.037 \\
\hline Median Hispanic or Latino Ethnicity (IQR) & $\begin{array}{l}20(8 \text { to } \\
30)\end{array}$ & $\begin{array}{l}32(18 \text { to } \\
58)\end{array}$ & 0.088 \\
\hline \multicolumn{4}{|l|}{ Median Language Spoken Percentage (IQR) } \\
\hline English & $\begin{array}{l}80(75 \\
\text { to } 87)\end{array}$ & $\begin{array}{l}80(71 \text { to } \\
92)\end{array}$ & 0.825 \\
\hline Spanish & $\begin{array}{l}12(8 \\
\text { to } 18)\end{array}$ & 14 (6 to 22$)$ & 0.570 \\
\hline Median MD or DO Full Time Equivalents (IQR) & $\begin{array}{l}8(5 \text { to } \\
10)\end{array}$ & $11(5$ to 16$)$ & 0.256 \\
\hline Median Nurse Practitioner Full Time Equivalents (IQR) & $\begin{array}{l}2(2 \text { to } \\
10)\end{array}$ & $6(1$ to 10$)$ & 0.898 \\
\hline Median Physician Assistant Full Time Equivalents (IQR) & $\begin{array}{l}0(0 \text { to } \\
1)\end{array}$ & $1(0$ to 2$)$ & 0.058 \\
\hline Median MD or DO Years in Practice (IQR) & $\begin{array}{l}15(10 \\
\text { to } 20)\end{array}$ & $\begin{array}{l}11(10 \text { to } \\
14)\end{array}$ & 0.101 \\
\hline Median Nurse Practitioner Years in Practice (IQR) & $\begin{array}{l}5(3 \text { to } \\
8)\end{array}$ & 10 (5 to 14$)$ & 0.100 \\
\hline Median Physician Assistant Years in Practice (IQR) & $\begin{array}{l}0(0 \text { to } \\
3)\end{array}$ & 5 (0 to 10$)$ & 0.255 \\
\hline $\begin{array}{l}\text { Implementing care pathways for symptom management is a top } \\
\text { priority of the department }\end{array}$ & $N=14$ & $N=9$ & \\
\hline Pediatric vs. Mixed Adult and Pediatric (\%) & $9(64 \%)$ & $7(78 \%)$ & 0.824 \\
\hline $\begin{array}{l}\text { Median Number Pediatric Cancer Patients Diagnosed Annually } \\
\text { (IQR) }\end{array}$ & $\begin{array}{l}83(62 \\
\text { to } 108)\end{array}$ & $\begin{array}{l}200(70 \text { to } \\
329)\end{array}$ & 0.122 \\
\hline \multicolumn{4}{|l|}{ Median Insurance Type Percentage (IQR) } \\
\hline Private & $\begin{array}{l}41(35 \\
\text { to } 52)\end{array}$ & $\begin{array}{l}50(24 \text { to } \\
59)\end{array}$ & 0.658 \\
\hline \multicolumn{4}{|c|}{ Abbreviations: IQR - interquartile range; MD - medical doctor; DO - doctor of osteopathy } \\
\hline
\end{tabular}




\begin{tabular}{|c|c|c|c|}
\hline & Agree* & $\begin{array}{l}\text { Neutral or } \\
\text { Disagree }\end{array}$ & $\begin{array}{l}\mathrm{P} \\
\text { Value }\end{array}$ \\
\hline Public & $\begin{array}{l}53(45 \\
\text { to } 64)\end{array}$ & $\begin{array}{l}46 \text { (41 to } \\
75)\end{array}$ & 0.658 \\
\hline No insurance & $\begin{array}{l}2 \text { ( }(0 \text { to } \\
5)\end{array}$ & $1(0$ to 3$)$ & 0.494 \\
\hline Median Male Percentage (IQR) & $\begin{array}{l}53(50 \\
\text { to } 59)\end{array}$ & $\begin{array}{l}53(50 \text { to } \\
55)\end{array}$ & 0.822 \\
\hline \multicolumn{4}{|l|}{ Median Race Percentage (IQR) } \\
\hline American Indian or Alaskan native & $\begin{array}{l}0 \text { (0 to } \\
1)\end{array}$ & $1(0$ to 1$)$ & 0.227 \\
\hline Asian & $\begin{array}{l}5 \text { (3 to } \\
10)\end{array}$ & 4 (3 to 8$)$ & 0.567 \\
\hline Black or African American & $\begin{array}{l}20 \text { (9 to } \\
25)\end{array}$ & 5 (4 to 10$)$ & 0.013 \\
\hline Native Hawaiian or other pacific islander & $\begin{array}{l}0(0 \text { to } \\
0)\end{array}$ & $1(0$ to 1$)$ & 0.040 \\
\hline White & $\begin{array}{l}70(58 \\
\text { to } 83)\end{array}$ & $\begin{array}{l}75 \text { (70 to } \\
88)\end{array}$ & 0.526 \\
\hline Median Hispanic or Latino Ethnicity (IQR) & $\begin{array}{l}28(14 \\
\text { to } 40)\end{array}$ & 26 (5 to 34$)$ & 0.636 \\
\hline \multicolumn{4}{|l|}{ Median Language Spoken Percentage (IQR) } \\
\hline English & $\begin{array}{l}78(71 \\
\text { to } 90)\end{array}$ & $\begin{array}{l}85 \text { ( } 75 \text { to } \\
89)\end{array}$ & 0.614 \\
\hline Spanish & $\begin{array}{l}15 \text { (9 to } \\
20)\end{array}$ & 10 (3 to 20$)$ & 0.591 \\
\hline Median MD or DO Full Time Equivalents (IQR) & $\begin{array}{l}9 \text { (6 to } \\
10)\end{array}$ & 12 (5 to 16$)$ & 0.449 \\
\hline Median Nurse Practitioner Full Time Equivalents (IQR) & $\begin{array}{l}3 \text { (2 to } \\
7)\end{array}$ & $9(1$ to 11$)$ & 0.292 \\
\hline Median Physician Assistant Full Time Equivalents (IQR) & $\begin{array}{l}0 \text { (0 to } \\
1)\end{array}$ & $1(0$ to 2$)$ & 0.222 \\
\hline Median MD or DO Years in Practice (IQR) & $\begin{array}{l}11(10 \\
\text { to } 15)\end{array}$ & $\begin{array}{l}12 \text { (10 to } \\
15)\end{array}$ & 0.974 \\
\hline
\end{tabular}

Abbreviations: IQR - interquartile range; MD - medical doctor; DO - doctor of osteopathy

* Rated on a 5-point Likert scale ranging from strongly disagree to strongly agree. Those who stated they agreed or strongly agreed were categorized as "agree" 


\begin{tabular}{|llll|}
\hline & Agree* & $\begin{array}{l}\text { Neutral or } \\
\text { Disagree }\end{array}$ & $\begin{array}{l}\text { P } \\
\text { Value }\end{array}$ \\
\hline Median Nurse Practitioner Years in Practice (IQR) & $\begin{array}{l}8(4 \text { to } \\
14)\end{array}$ & $7(4$ to 10) & 0.704 \\
\hline Median Physician Assistant Years in Practice (IQR) & $\begin{array}{l}2(0 \text { to } \\
10)\end{array}$ & $5(0$ to 5$)$ & 0.893 \\
\hline Abbreviations: IQR - interquartile range; MD - medical doctor; DO - doctor of osteopathy & \\
\hline $\begin{array}{l}\text { * Rated on a 5-point Likert scale ranging from strongly disagree to strongly agree. Those who stated } \\
\text { they agreed or strongly agreed were categorized as "agree" }\end{array}$ & \\
\hline
\end{tabular}

\section{Discussion}

In this study, we found that few survey respondents anticipated challenges with supportive care implementation. However, potential barriers that were reported lay within the implementation climate construct of CFIR and were lack of support, recognition and prioritization at the participating institutions. Lack of person-time to create care pathways and champion their use, lack of physician interest, and lack of information technology were other important potential barriers reported with respect to developing and implementing symptom management care pathways. However, the COVID-19 pandemic does not appear to be perceived as a major barrier to research conduct.

We found that unfavorable implementation climate may be a potential barrier to care pathway implementation. Other studies have also identified this construct as a potential problem in program implementation.[19, 20] It is interesting that smaller sites reported receiving more support for care pathway implementation. It is possible that smaller sites are more likely to provide verbal and non-verbal support of initiatives in general and if this is true, identifying ways to provide this type of support across institutions could be important. Such support could include wide availability of research staff to address questions and provide educational materials. It may also be important to identify site champions who can provide this type of support locally. The finding of greater support at institutions with a greater percentage of black patients may be spurious. It also may reflect additional supports given to institutions that are minority based National Cancer Institute Community Oncology Research Program sites.

We found that the COVID-19 pandemic did not appear to be a major barrier to research conduct. This finding is in contrast to a recent meta-analysis suggesting that trial delays and cessation were common and were a direct consequence of the pandemic.[21] Our findings may differ because the survey was distributed later in the pandemic, when many institutions had adapted to it. Further, some institutions have made distinctions based upon whether research activities are in person vs. not in person and whether they are essential vs. not essential. Given that our trial could be conducted entirely remotely, and since some could consider this type of trial essential, respondents may have anticipated fewer barriers compared with other research studies. 
The strengths of this study include the utilization of an established framework (CFIR) in addition to studyspecific items in order to identify potential barriers to care pathway implementation. This will allow important contextual elements to be evaluated for their future relationship to implementation strategies and outcomes. Another strength is the evaluation of the impact of the COVID-19 pandemic on clinical research, a timely and important question. However, the study is limited as two institutions either dropped out or did not complete the survey; they are likely to be different than the 23 institutions that did complete the survey. In addition, these questions were mainly answered by a single individual, namely the site principal investigator. Perspectives of other healthcare professionals at the site could be different. Finally, sites agreed to provide support at the grant submission stage, suggesting they believe that symptom management is important. Thus, participating sites are likely a positively biased cohort and the "typical" site may report more barriers to care pathway implementation.

\section{Conclusions}

In conclusion, respondents at pediatric oncology institutions expected few barriers to symptom management care pathway implementation at their institutions. The most commonly reported barriers to implementation were lack of support, recognition and prioritization. The COVID-19 pandemic was not a major barrier to clinical research activities in pediatric oncology.

\section{Abbreviations}

CFIR - Consolidated Framework for Implementation Research

CPG - Clinical Practice Guideline

SSPedi - Symptom Screening in Pediatrics Tool

SPARK - Supportive care Prioritization, Assessment and Recommendations for Kids

COVID-19 - Coronavirus disease pandemic

\section{Declarations}

Ethics approval and consent to participate: This study has research ethics board approval from The Hospital for Sick Children Research Ethics Board (\#1000068699) and was performed in accordance with the Declaration of Helsinki.

Consent for publication: Not applicable

Availability of data and materials: The datasets used or analyzed during the current study are available from the corresponding author on reasonable request.

Competing interests: The authors declare that they have no competing financial interests. 
Funding: The study was supported by operating grants from the Canadian Institutes of Health Research (PJT 169165) and the National Institutes of Health (1R01CA251112). The funding body had not role in the design of the study; collection, analysis and interpretation of data; and in writing the manuscript.

Authors' contributions: All authors LD, AG, EV, LMK and LS were involved in material design and procedures. LS drafted the manuscript, all authors reviewed, revised and approved the manuscript.

Acknowledgements: We are grateful to the people who agreed to champion our study at their institutions and thank those who responded to our surveys. LS is supported by the Canada Research Chair in Pediatric Oncology Supportive Care. The study was supported by operating grants from the Canadian Institutes of Health Research (PJT 169165) and the National Institutes of Health (1R01CA251112).

\section{References}

1. Dupuis LL, Johnston DL, Baggott C, Hyslop S, Tomlinson D, Gibson P, et al. Validation of the Symptom Screening in Pediatrics Tool in Children Receiving Cancer Treatments. J Natl Cancer Inst. 2018;110(6):661-8.

2. Hyslop S, Davis H, Duong N, Loves R, Schechter T, Tomlinson D, et al. Symptom documentation and intervention provision for symptom control in children receiving cancer treatments. Eur $\mathrm{J}$ Cancer. 2019;109:120-8.

3. Sung L. Priorities for quality care in pediatric oncology supportive care. J Oncol Pract. 2015;11(3):187-9.

4. Dupuis LL, Cook S, Robinson PD, Tomlinson D, Vettese E, Sung L. Optimizing symptom control in children and adolescents with cancer. Pediatr Res. 2019;86(5):573-8.

5. Tomlinson D, Dupuis LL, Gibson P, Johnston DL, Portwine C, Baggott C, et al. Initial development of the Symptom Screening in Pediatrics Tool (SSPedi). Support Care Cancer. 2014;22(1):71-5.

6. O'Sullivan C, Dupuis LL, Gibson P, Johnston DL, Baggott C, Portwine C, et al. Refinement of the symptom screening in pediatrics tool (SSPedi). Br J Cancer. 2014;111(7):1262-8.

7. O'Sullivan C, Lee Dupuis L, Gibson P, Johnston DL, Baggott C, Portwine C, et al. Evaluation of the electronic self-report Symptom Screening in Pediatrics Tool (SSPedi). BMJ Support Palliat Care. 2018;8(1):110-6.

8. Cook S, Vettese E, Tomlinson GA, Soman D, Schechter T, Kuczynski S, et al. Feasibility of a randomized controlled trial of symptom screening and feedback to healthcare providers compared with standard of care using the SPARK platform. Support Care Cancer. 2020;28(6):2729-34.

9. Vettese E, Cook S, Soman D, Kuczynski S, Spiegler B, Davis H, et al. Longitudinal evaluation of Supportive care Prioritization, Assessment and Recommendations for Kids (SPARK), a symptom screening and management application. BMC Cancer. 2019;19(1):458.

10. Cook S, Vettese E, Soman D, Hyslop S, Kuczynski S, Spiegler B, et al. Initial development of Supportive care Assessment, Prioritization and Recommendations for Kids (SPARK), a symptom 
screening and management application. BMC Med Inform Decis Mak. 2019;19(1):9.

11. Lu X, Zhang L, Du H, Zhang J, Li YY, Qu J, et al. SARS-CoV-2 Infection in Children. N Engl J Med. 2020;382(17):1663-5.

12. Guan WJ, Ni ZY, Hu Y, Liang WH, Ou CQ, He JX, et al. Clinical Characteristics of Coronavirus Disease 2019 in China. N Engl J Med. 2020;382(18):1708-20.

13. Clinical Practice Guidelines. Directions for a New Program, Institute of Medicine. Washington, DC: National Academy Press; 1990.

14. Clinical Practice Guidelines We Can Trust. Washington, D.C.: Institute of Medicine, National Academies Press; 2011.

15. Guyatt GH, Oxman AD, Vist GE, Kunz R, Falck-Ytter Y, Alonso-Coello P, et al. GRADE: an emerging consensus on rating quality of evidence and strength of recommendations. BMJ. 2008;336(7650):924-6.

16. Campbell H, Hotchkiss R, Bradshaw N, Porteous M. Integrated care pathways. BMJ. 1998;316(7125):133-7.

17. Damschroder LJ, Aron DC, Keith RE, Kirsh SR, Alexander JA, Lowery JC. Fostering implementation of health services research findings into practice: a consolidated framework for advancing implementation science. Implement Sci. 2009;4:50.

18. Fernandez ME, Walker TJ, Weiner BJ, Calo WA, Liang S, Risendal B, et al. Developing measures to assess constructs from the Inner Setting domain of the Consolidated Framework for Implementation Research. Implement Sci. 2018;13:52.

19. Stokes T, Tumilty E, Doolan-Noble F, Gauld R. HealthPathways implementation in a New Zealand health region: a qualitative study using the Consolidated Framework for Implementation Research. BMJ Open. 2018;8(12):e025094.

20. Robey N, Margolies S, Sutherland L, Rupp C, Black C, Hill T, et al. Understanding staff- and systemlevel contextual factors relevant to trauma-informed care implementation. Psychol Trauma [Internet]. 2020. Available from: https://www.ncbi.nlm.nih.gov/pubmed/32915041.

21. Sathian B, Asim M, Banerjee I, Pizarro AB, Roy B, van Teijlingen ER, et al. Impact of COVID-19 on clinical trials and clinical research: A systematic review. Nepal J Epidemiol. 2020;10(3):878-87.

\section{Supplementary Files}

This is a list of supplementary files associated with this preprint. Click to download.

- AdditionalFile1.docx 